\title{
Deposition of Nanoscopically Smooth DLC Tool Coatings for Dry Forming of Aluminum Sheets
}

\author{
TIM ABRAHAM,${ }^{1,3}$ INGMAR BIALUCH, ${ }^{1}$ GÜNTER BRÄUER, ${ }^{1}$ \\ FELIX FLEGLER, ${ }^{2,4}$ and PETER GROCHE ${ }^{2}$ \\ 1.-Fraunhofer Institute or Surface Engineering and Thin Films IST, Bienroder Weg 54 E, \\ 38108 Brunswick, Germany. 2.-Institute for Production Engineering and Forming \\ Machines, Technische Universität Darmstadt, Otto-Berndt-Straße 2, 64287 Darmstadt, Germany. \\ 3.—e-mail: tim.abraham@ist.fraunhofer.de.4.—e-mail: flegler@ptu.tu-darmstadt.de
}

Recent investigations demonstrated the applicability of diamond-like carbon (DLC)-coated tools for dry forming of aluminum, which is a challenging application field due to the high adhesion tendency of aluminum. An exceptionally low roughness of the coated forming tool is required to prevent adhesion-induced tool failure. To establish dry forming of aluminum in industrial production processes, efficient methods must be developed to manufacture DLC-coated forming tools with reproducible high surface quality. This paper illustrates two DLC coating processes that are especially optimized for deposition of nanoscopically smooth DLC tool coatings. Two optimized coating systems were deposited, characterized, and subsequently evaluated using application-oriented strip drawing tests to validate their performance in comparison with a state-of-the-art coating system. One coating process showed high potential for production of DLC-coated forming tools with the required surface quality.

\section{INTRODUCTION}

The application fields of aluminum are continuously widening due to an ongoing trend towards lightweight construction. One of the most prominent drivers of this trend is global warming. In many cases, component weight influences the energy consumption and associated $\mathrm{CO}_{2}$ emissions during the use phase of a product. Forming and machining of aluminum as a construction material requires larges amount of lubricants to ensure a high production rate and good product quality. Although a broad spectrum of sustainable lubricants are available, the lowest environmental impact can only be achieved by realizing dry process conditions. ${ }^{1}$ However, forgoing the usage of lubricants leads to rapid formation of aluminum adhesion onto the tool surface and often immediate tool failure. ${ }^{2}$ Thus, effective strategies must be developed to improve the tribological conditions in dry sheet metal forming processes for aluminum by considering the relevant wear mechanisms and influencing parameters.
One strategy is the deposition of hard thin films to optimize the tribological properties of forming tools. Diamond-like carbon (DLC) coatings and, in case of this investigation, the subclass of amorphous hydrogenated carbon (a-C:H) coatings are well known for their exceptional tribological properties in combination with a low friction value and high wear resistance. ${ }^{3}$ Several studies have reported these properties also for sliding contacts against aluminum. ${ }^{4}$ Nevertheless, a-C:H-coated forming tools still fail due to rapid formation of aluminum adhesions comparably to uncoated forming tools. ${ }^{5}$ Preliminary investigations identified the nanoscopic surface roughness of a-C:H-coated forming tools as one reason for such rapid adhesion formation. ${ }^{6-9}$ Subsequent investigations with nanoscopically smooth a-C:H-coated forming tools finally demonstrated the feasibility of dry aluminum sheet forming. ${ }^{1}$ The high surface quality was achieved by manual polishing after coating deposition. However, this method requires accurate quality control using sophisticated measuring techniques such as atomic force microscopy (AFM) to ensure a homogeneous surface quality. Thus, the practicability of this 
method for industrial forming tools is restricted, especially when it comes to tools with higher geometrical complexity and larger dimensions. Furthermore, the deliberate decrease of the tool lifetime as a result of the coating thickness reduction is another disadvantage.

In the work described herein, alternative methods to manufacture a-C:H-coated forming tools with the desired surface quality were investigated. Instead of manual polishing, nanoscopic roughness was achieved by plasma etching. This technology is typically applied for surface conditioning of the substrate prior to coating deposition. As part of the posttreatment process, plasma etching allows selective removal of the coating material, offering the opportunity to adjust the surface roughness. ${ }^{10,11}$ Meanwhile, the second method aims to directly deposit nanoscopically smooth a-C:H coatings on tools. ${ }^{12,13}$ The complete coating architecture and deposition parameters are changed to avoid formation of nanoscopic asperities as a result of the coating growth process. Using these methods, test samples for tribological tests were coated and tested under application-oriented conditions to evaluate their potential to enable dry aluminum sheet forming more effectively.

\section{EXPERIMENTAL PROCEDURES}

\section{Materials}

The sheet material was aluminum EN AW-5083 with a mill-finish surface and sheet thickness of $1.5 \mathrm{~mm}$. This material is used in a wide range of applications such as vehicles, tanks, and apparatus construction. Thus, this investigation represents a wide variety of use cases. The strip drawing tools were made of heat-treated Vanadis 4 Extra SuperClean (Van4E), which is a powder metallurgical cold-work steel. In addition to the tools, flat samples made of the same steel material were used for subsequent coating characterization.

Table I presents some of the mechanical properties. Prior to coating deposition, the tools and samples were polished using $3-\mu \mathrm{m}$ diamond suspension and cleaned with ethanol.

\section{Coating Deposition}

Three different kinds of a-C:H coating system were tested as shown schematically in Fig. 1. The referential coating system (REF) was tested in preliminary investigations. ${ }^{2,14,15}$ For its deposition, a physical vapor deposition (PVD) process was combined with a plasma-assisted chemical vapor deposition (PACVD) process. Further information about the deposition process is given in Ref. 14.

The second a-C:H coating system (PE) is a derivative of the reference coating system. In an additional process step, the coated toolset was treated with an argon-based high-frequency plasma at constant bias voltage of $-200 \mathrm{~V}$ for $30 \mathrm{~min}$. The objective of this third process is to deposit an a-C:H coating system with an intrinsically nanoscopically smooth surface (IS). Therefore, the titanium adhesion layer was replaced by a silicon-modified amorphous carbon coating (a-C:H:Si) with thickness of $0.2 \mu \mathrm{m}$, which excels in achieving a good adhesion tendency for metallic materials. The interlayer was deposited using a PACVD process with tetramethylsilane $\mathrm{Si}\left(\mathrm{CH}_{3}\right)_{4}$. In comparison with the titanium interlayer having columnar growing structure, the a-C:H:Si layer shows in general an amorphous growing structure with a smoother surface, which will also affect the resulting roughness of the a-C:H functional layer. ${ }^{10}$

\section{Coating and Surface Characterization}

The coating properties were analyzed using an additional flat sample. The coating hardness $\mathrm{HUpl}$ was determined by using a commercial instrument (Fischerscope H 100) to record load versus depth curves up to $30 \mathrm{mN}$. To evaluate the adhesive strength of the a-C:H coating to the tool surface, Rockwell tests were conducted according to ISO 26443 , classifying the strength from 1 (high adhesive strength) up to 6 (very low adhesive strength). The coating thickness was measured by scanning a tactile measurement system (Bruker DektakXT) across a coated and uncoated surface area. The coating properties are presented in Table II. In case of the PE coating, the thickness was slightly thinner (by $25 \mathrm{~nm}$ ) in comparison with the REF coating.

After polishing and prior to coating deposition, the surface roughness of the tools and samples was analyzed using the tactile measurement system (Form Talysurf Series 2) according to DIN EN ISO 4287, yielding an arithmetical surface roughness $R_{\text {a }}$ of $13 \mathrm{~nm}$. After coating deposition, the roughness of the a-C:H coatings was determined by atomic force microscopy (Bruker Veeco Dimension 3100) in tapping mode over an area of $50 \mu \mathrm{m} \times 50 \mu \mathrm{m}$. The collected data were filtered using a gaussian algorithm to eliminate the superposed macroscopic

Table I. Material properties of the sheet metal and tools

\begin{tabular}{|c|c|c|c|c|c|c|}
\hline Material & Short symbol & $\boldsymbol{R}_{\mathrm{m}}(\mathbf{M P a})$ & $R_{\mathrm{p0.2}}(\mathrm{MPa})$ & HRC & Material condition & Surface finish \\
\hline $\begin{array}{l}\text { EN AW-5083 } \\
\text { Vanadis } 4 \text { extra }\end{array}$ & 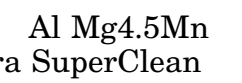 & $\begin{aligned} &> 275 \\
&-\end{aligned}$ & $>>-$ & $\overline{60}$ & $\begin{array}{c}\mathrm{O} \\
\text { Hardened }\end{array}$ & $\begin{array}{l}\text { Mill finish as well as polished } \\
\text { Polished and coated }\end{array}$ \\
\hline
\end{tabular}




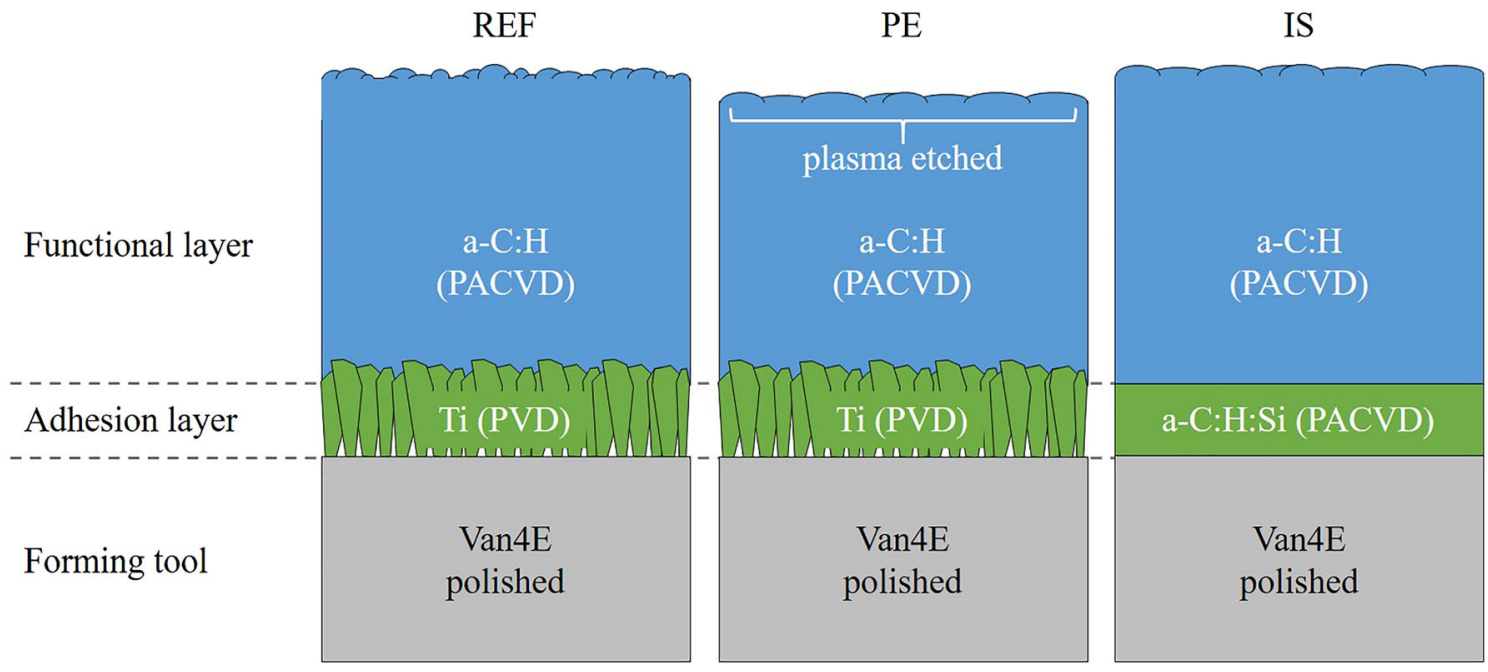

Fig. 1. Architecture of deposited a-C:H coating systems.

Table II. Properties of a-C:H coating systems

\begin{tabular}{|c|c|c|c|}
\hline a-C:H coating system & Hardness (GPa) & Thickness $(\mu \mathrm{m})$ & Adhesion class \\
\hline $\mathrm{REF}$ & 32 & 2.2 & 1 \\
\hline $\mathrm{PE}$ & 32 & $<2.2$ & 1 \\
\hline IS & 32 & 2.6 & 4 \\
\hline
\end{tabular}
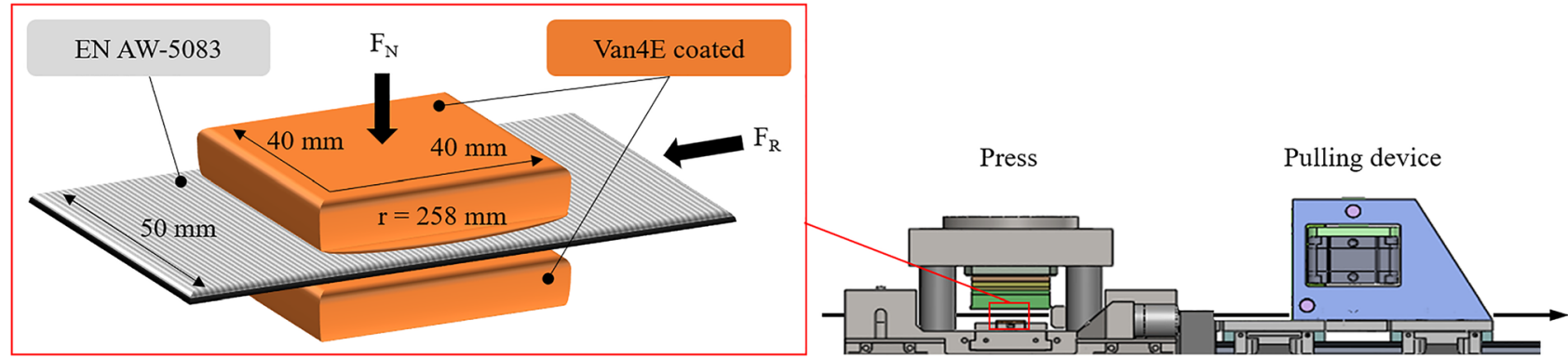

Fig. 2. Schematic of strip drawing test for tribological evaluation of a-C:H tool coatings.

roughness of the tool surface. Afterwards, the roughness values were calculated according to DIN EN ISO 25178 and averaged based on three separate measurements.

\section{Tribological Tests}

Strip drawing tests were conducted for tribological evaluation of the a-C:H coatings under nearapplication conditions. The strip drawing test enables emulation of the typical tribological load spectrum of the deep drawing and stretch forming processes. ${ }^{16}$ Figure 2 shows the test principle, in which a pressure is applied to a strip of sheet material by an upper and lower tool while the strip is drawn with a defined sliding speed and sliding distance. The cylinder-plane geometry of the toolset simulates the conditions at the die radius of a deep drawing tool. The upper tool is cylindrically shaped with radius of $258 \mathrm{~mm}$, and the lower tool is flat. Both parts have a basic surface area of $40 \mathrm{~mm} \times 40 \mathrm{~mm}$.

The test parameters were deduced from an industrial forming process of EN AW-5083 aluminum sheets. A load of $9 \mathrm{kN}$ was applied, leading to an initial contact stress of $100 \mathrm{MPa}$ with an average velocity of $50 \mathrm{~mm} \mathrm{~s}^{-1}$ and a sliding distance of $100 \mathrm{~mm}$ per stroke. Before each test, the substrates were cleaned using ethanol and acetone to ensure a dry and technically pure contact during the tribometer tests. 


\section{RESULTS AND DISCUSSION}

\section{Surface Roughness}

Previous investigations identified the nanoscopic surface roughness of a-C:H-coated forming tools as an important factor influencing the adhesion tendency of aluminum during deep drawing processes. ${ }^{6,17}$ Figure 3 shows the surface topography and roughness of the deposited a-C:H coating systems. REF showed the typical surface topography of an a-C:H coating system with a metallic interlayer, characterized by dome-shaped asperities. ${ }^{10,18}$ The surface roughness of PE was smoother due to the plasma etching. Comparing the topography and roughness values of REF with $\mathrm{PE}$, the etching process appeared to be more intensive at asperities, leading to a reduced arithmetical mean height $\left(S_{\mathrm{a}}\right)$ and reduced peak height $\left(S_{\mathrm{pk}}\right)$. However, the maximum height $\left(S_{z}\right)$ and the standard deviations were high, indicating inhomogeneous material removal across the tool surface. In the case of the IS coating, the adjustment of the coating architecture resulted in a significantly reduced roughness values. Its arithmetical mean height and maximum height actually surpassed the surface properties of the polished a-C:H coating $\left(S_{\mathrm{a}} 18 \pm 3.3 \mathrm{~nm}, S_{z}\right.$ $227 \pm 112 \mathrm{~nm}, S_{\mathrm{pk}} 14 \pm 6.9 \mathrm{~nm}$ ), which has already been qualified for dry forming processes of aluminum. ${ }^{1}$ However, the reduced peak height was still nearly doubled.

On all coated tools, plateau-shaped asperities were observable, especially highlighted in the visualization of the IS coating system in Fig. 3. These asperities were caused by the carbide precipitates of the cold-work steel Van4E, which is less abraded during the polishing process. After the coating deposition, they still protruded by $50 \mathrm{~nm}$ up to $100 \mathrm{~nm}$ from the tool surface, leading to higher roughness values. In particular, the $\mathrm{REF}$ and $\mathrm{PE}$ coating systems seemed to be more affected by these precipitates, which may result from the growing structure of the titanium interlayer. ${ }^{19}$

\section{Tribological Evaluation}

The tribological properties of the deposited a-C:H coating systems were evaluated by strip drawing tests (Fig. 4). In all the tests, aluminum adhesions formed on the coated tools during the first dry stroke. Meanwhile, the coefficient of friction (COF) increased above 0.2. According to Ref. 20, COF values $>0.2$ exceed the tolerable value for sheet metal forming processes due to an undesirable increase of the shear stress within the bulk material. In real forming processes, such tribological properties would lead to significantly reduced drawing ratios (limited by cup base fracture) and insufficient surficial and geometrical quality of the aluminum parts, implying immediate tool failure for all the coating systems. Considering the prior publications, the tribological properties of REF are typical and illustrate the current need for improvement. However, PE showed no noticeable change of the tribological behavior, leading to the conclusion that the smoothening effect of the plasma etching was insufficient. Although promising process parameters obtained from recent investigations were applied, the resulting surface topography of $\mathrm{PE}$ differed. This result is probably due to the change of the tool material with smaller precipitates, or the change in the tool geometry. It is well known that the substrate geometry influences the plasma conditions at its surface. ${ }^{12}$ Thus, the etching efficiency also changed. Future experiments should explore adjustment of the process parameters as a function of the tool geometry and evaluate the performance of tool materials without precipitates.

In comparison with REF and $\mathrm{PE}$, the $\mathrm{COF}$ and the tendency for aluminum adhesion were noticeably lower for the IS specimen. The scanning electron microscopy (SEM) images of the wear tracks in Fig. 5 illustrate the reason for the improved tribological performance. The REF coating system showed aluminum adhesion at the plateau-shaped asperities caused by the precipitates, as well as the dome-shaped native asperities of the coating

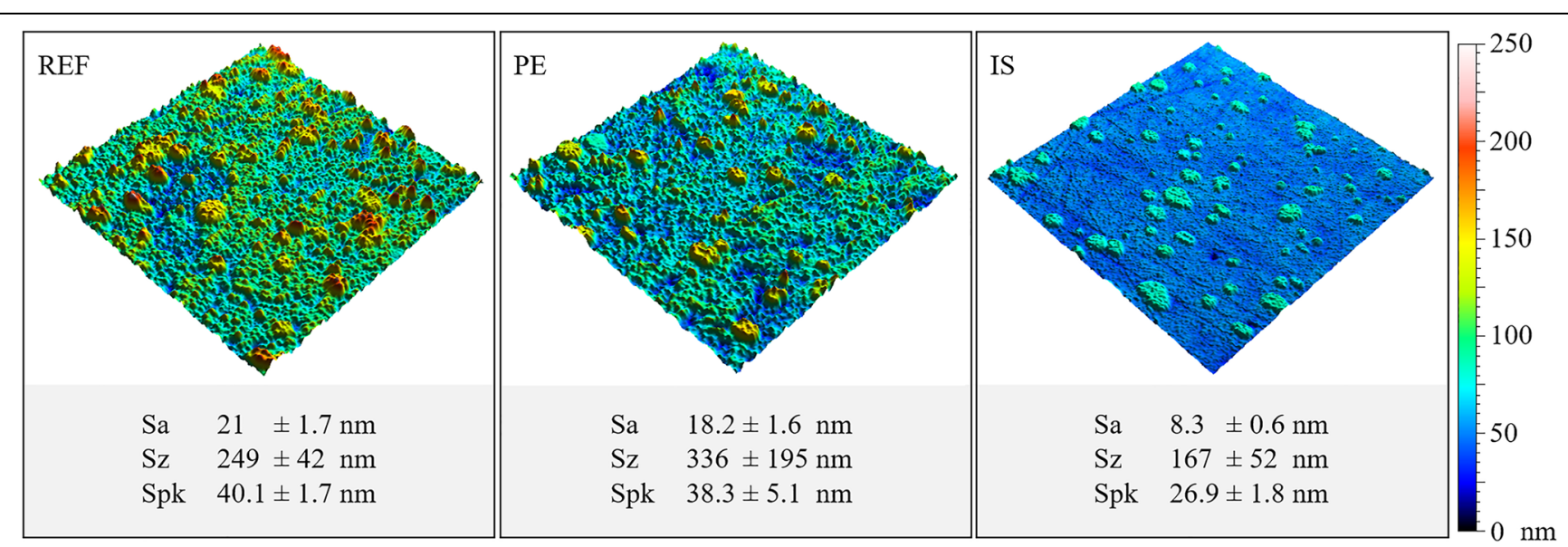

Fig. 3. AFM measurements of a-C:H-coated strip drawing tools: Visualizations (resulting area size of $27.5 \mu \mathrm{m} \times 27.5 \mu \mathrm{m}$ after filtering) and average roughness values. 

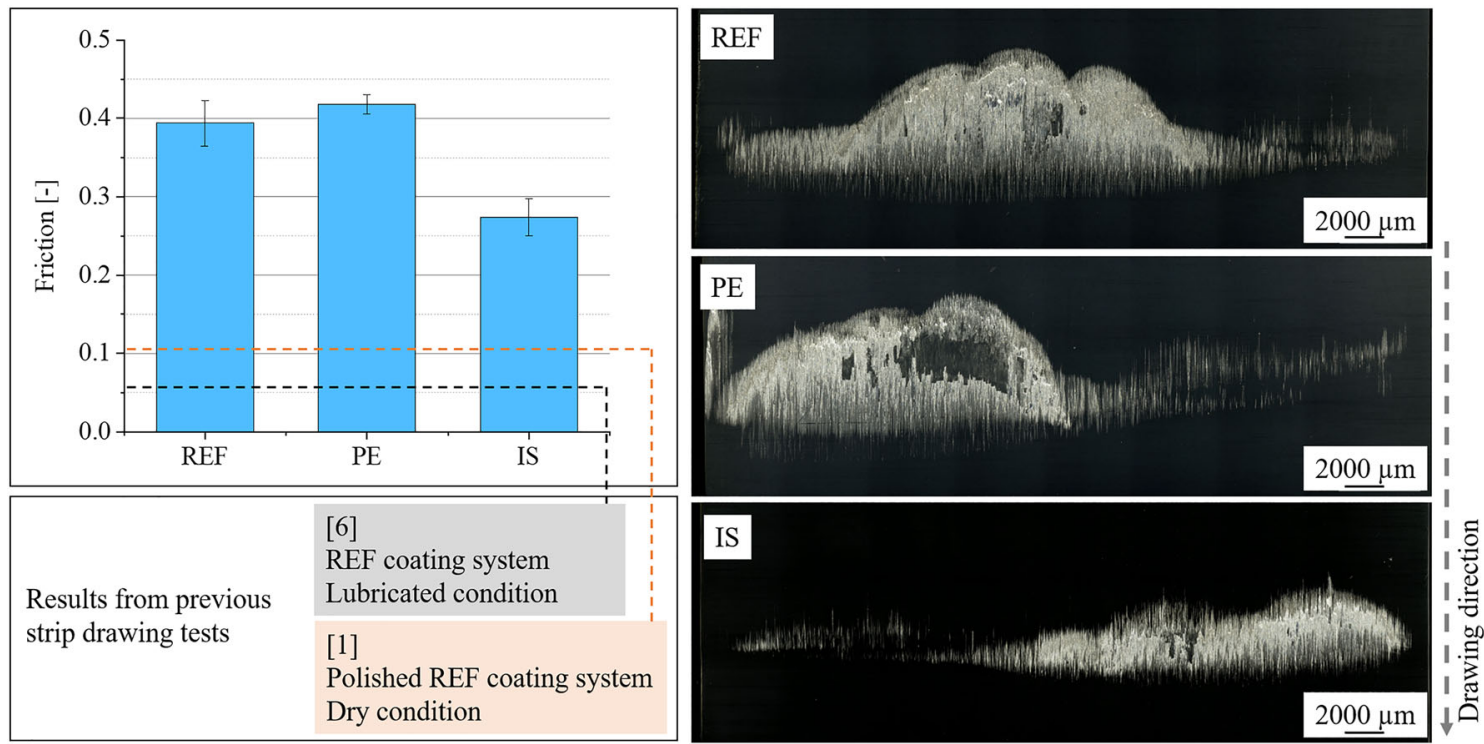

Fig. 4. Comparison of tribological performance of three different a-C:H coating systems based on strip drawing tests after a single stroke: average friction values and microscope pictures of the wear track (cylindrical tool part).
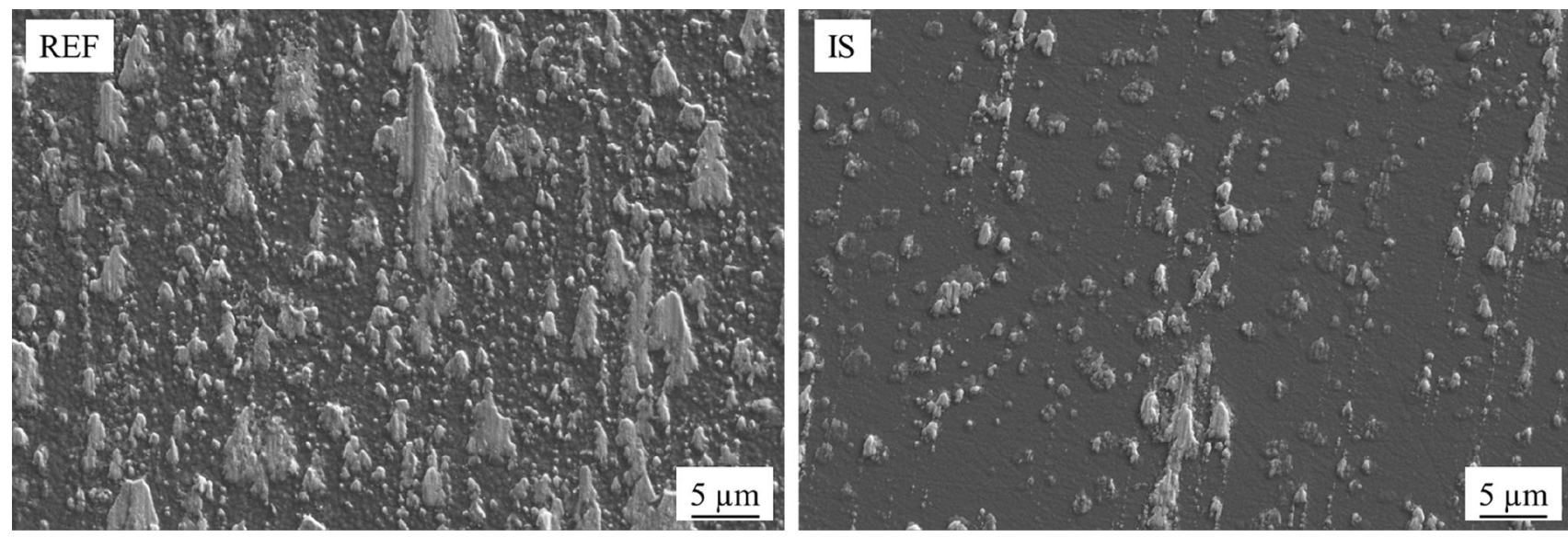

Fig. 5. SEM images of wear tracks after a single stroke.

system. In case of the IS coating system, adhesions were mainly formed at the plateau-shaped asperities, leading to a significantly reduced adhesion density and sliding resistance. The interdependencies between the adhesion growth and the surface properties of a-C:H coatings are discussed in detail in Refs. ${ }^{17},{ }^{21}$. Disintegration of the aluminum oxide layer by asperities on the tool surface is postulated to be the first step of the aluminum adhesion process. Therefore, the superposed asperities, which originated from the tool material selection, are probably the main reason for the tool failure. Thus, the tribological properties of the IS coating system possibly have high potential to enable dry forming of aluminum. Analogous to the recommendation for the PE coating system, tool materials without precipitates should be used to validate the tribological properties of the IS coating system.
The IS coating system surpassed in some regards the roughness properties of the polished a-C:H coating but failed to prevent adhesion of the aluminum. The surface roughness and tribological properties can be correlated with the reduced peak height. As already postulated in Refs. ${ }^{6}, 17,21$, this value indicates the penetration depths of the asperities into the aluminum surface, leading to microplowing and delamination of the aluminum passivation layer, and subsequently adhesion formation in contact with the reactive aluminum matrix. The findings of this work also support this hypothesis, i.e., that there is a critical roughness threshold below which the tribological properties in contact with aluminum drastically improve. This threshold thus lies between $26.9 \mathrm{~nm}$ and the reduced peak height of $14 \mathrm{~nm}$. However, these values were determined using steel alloys with 
carbide precipitates. How these precipitates affect the threshold is unknown. Thus, additional tribological tests and surface characterizations with precipitation-free tool materials are needed to specify the threshold for a precise forecast of the tribological performance in dry forming processes.

\section{CONCLUSION}

Recent investigations demonstrated successful dry forming of aluminum sheets by using a-C:Hcoated and subsequently polished forming tools. However, the required process and quality control for the polishing of the a-C:H coating is currently inefficient and decreases the attractiveness of this route for commercialization. Two alternative methods to manufacture a-C:H-coated forming tools with the desired surface quality were investigated in this work. The first tested method introduced a plasma etching process as a posttreatment procedure of a$\mathrm{C}: \mathrm{H}$-coated forming tools. Measurements indicated preferential material removal from asperities, resulting in an inhomogeneous roughness reduction. The second method was an optimization of the a-C:H coating architecture by replacing the PVDbased metallic adhesion layer with a PACVD-based a-C:H:Si layer. The amorphous growth structure of this interlayer led to significantly lower roughness of the a-C:H coating system, nearly matching the surface quality of the polished a-C:H tool coating.

Both methods were evaluated using applicationoriented strip drawing tests, revealing an insufficient improvement of the tribological properties to enable dry forming of aluminum. The process parameters of the plasma etching were derived from previous investigations with a differing substrate geometry. The geometry possibly influenced the plasma condition and thereby the efficiency and effect of the etching process. In future work, the etching parameters should be optimized as a function of the tool geometry. In the case of the a-C:H coating system with a natively smooth surface roughness, the friction value and adhesion tendency were noticeably reduced. More detailed analysis of the worn tool surface revealed a very low adhesion tendency for the optimized coating system, which was negatively affected by the superposing asperities of the protruding carbide precipitates of the cold-work steel. Thus, steel materials without precipitates should be used in future investigations. Furthermore, the tribological properties of the coated tools correlated with their reduced peak height, indicating a threshold below which dry sheet metal forming of aluminum can be realized.

\section{ACKNOWLEDGEMENTS}

Open Access funding provided by Projekt DEAL. The authors thank the German Research Foundation (DFG) for funding of the project "Functionalizing of a-C:H tool coatings and homogenization of the aluminium passive layer for the dry forming of aluminum" received within the priority program SPP 1676 "Dry metal forming-sustainable production through dry processing in metal forming".

\section{OPEN ACCESS}

This article is licensed under a Creative Commons Attribution 4.0 International License, which permits use, sharing, adaptation, distribution and reproduction in any medium or format, as long as you give appropriate credit to the original author(s) and the source, provide a link to the Creative Commons licence, and indicate if changes were made. The images or other third party material in this article are included in the article's Creative Commons licence, unless indicated otherwise in a credit line to the material. If material is not included in the article's Creative Commons licence and your intended use is not permitted by statutory regulation or exceeds the permitted use, you will need to obtain permission directly from the copyright holder. To view a copy of this licence, visit http://creativecommons.org/licenses/by/4.0/.

\section{REFERENCES}

1. T. Abraham, G. Bräuer, F. Flegler, P. Groche, M. Demmler, Procedia Manuf. To be publ, 8 (2020).

2. T. Abraham, G. Bräuer, F. Kretz, P. Groche, Tribological investigation of silicon-modified DLC coatings for the dry forming of aluminum alloys, in 12th International Conference on THE"A" Coatings ed. by K. Bobzin, B. K.-D., D. B., M. H.J., M. M. (PZH Verlag, Hannover, 2016), p. 8.

3. K. Bewilogua and D. Hofmann, Surf. Coat. Technol. 242, 214 (2014).

4. C. Donnet, A. Erdemir, Tribology of Diamond-Like Carbon Films, in ed. by C. Donnet, A. Erdemir (Springer US, Boston, MA, 2008).

5. R. Zhao, J. Steiner, K. Andreas, M. Merklein, and S. Tremmel, Tribol. Int. 118, 484 (2018).

6. T. Abraham, G. Bräuer, F. Kretz, and P. Groche, MATEC Web Conf. 190, 14001 (2018).

7. J. Heinrichs, M. Olsson, and S. Jacobson, Wear 302, 1249 (2013).

8. J. Heinrichs and S. Jacobson, Tribol. Lett. 46, 299 (2012).

9. J. Heinrichs, M. Olsson, and S. Jacobson, Tribol. Lett. 50, 431 (2013).

10. M.C. Salvadori, D.R. Martins, and M. Cattani, Surf. Coat. Technol. 200, 5119 (2006).

11. M. Moseler, O. Rattunde, J. Nordiek, and H. Haberland, Nucl. Instrum. Methods Phys. Res. Sect. B Beam Interact. Mater. Atoms 164, 522-536 (2000).

12. N. Nelson, R.T. Rakowski, J. Franks, P. Woolliams, P. Weaver, and B.J. Jones, Surf. Coat. Technol. 254, 73 (2014).

13. Y. Lifshitz, R. Edrei, A. Hoffman, E. Grossman, G.D. Lempert, J. Berthold, B. Schultrich, and H.U. Jäger, Diam. Relat. Mater. 16, 1771 (2007).

14. K. Taube, Surf. Coat. Technol. 98, 976 (1998).

15. A. Hieke, K. Bewilogua, K. Taube, I. Bialuch, K. Weigel, Efficient deposition technique for diamond-like carbon coatings, in 43rd Annual Technical Conference (Society of Vacuum Coaters, Denver, 2000), pp. 301-304.

16. P. Groche and G. Nitzsche, Materwiss. Werkst. 35, 461 (2004).

17. J. Heinrichs, Chem. 70 (2012).

18. S.J. Harris, A.M. Weiner, C.H. Olk, and M. Grischke, Wear 219, 98-104 (1998).

19. A. Anders, Thin Solid Films 518, 4087 (2010).

20. E. Doege and B.-A. Behrens, Handbuch Umformtechnik (Berlin: Springer, 2010). 
21. T. Abraham, Entwicklung von Kohlenwasserstoffschichten für die schmiermittelfreie Kaltumformung von Aluminiumblechen durch Tiefziehen (Stuttgart: Fraunhofer Verlag, 2019).
Publisher's Note Springer Nature remains neutral with regard to jurisdictional claims in published maps and institutional affiliations. 